tăng huyết áp [7].

Nghiên cứu của chúng tôi cũng phù hợp với nghiên cứu của tác giả Nguyễn Lân Việt năm cũng cho thấy rằng những người có BMI từ $25 \mathrm{~kg} / \mathrm{m}^{2}$ trở lên có nguy cớ THA cao hơn so với người có $B M I<25 \mathrm{~kg} / \mathrm{m}^{2}$ (chuẩn là 1,61 lần), người có $B M I \geq 25 \mathrm{~kg} / \mathrm{m}^{2}$ có nguy cơ THA hơn (chuẩn) là 5,2 lần [5].

Bảng 3.5 cho thấy tỷ lệ tăng huyết áp phát hiện mới là $38,5 \%$, tỷ lệ này khá tương đồng so với nghiên cứu của tác giả Bochud Murielle và cộng sự $(35,9 \%)$ [6]; thấp hơn nghiên cứu tỷ lệ tăng huyết áp của tác giả Trần Văn Huy $(51,6 \%)$. Điều này cho thây ý thức người dân về bệnh tăng huyết áp được nâng cao qua các đợt truyền thông của chiến lược quốc gia phòng chống bệnh không lây nhiễm trong đó có tăng huyết áp [3]. Theo báo cáo của Bộ Y tế tại Hội nghi về công tác phòng, chống bệnh không lây nhiễm, ở Việt Nam, các BKLN đã chiếm đến $66 \%$ tổng gánh nặng bệnh tật và $73 \%$ tổng số ca tử vong hằng năm. Có đển $60 \%$ người mắc tăng huyết áp chưa được phát hiện bệnh, chỉ có $14 \%$ bệnh nhân THA và gần $30 \%$ người có nguy cơ tim mạch được quản lý, dự phòng và dùng thuốc theo quy định, có một tỷ lệ lớn về THA được phát hiện tình cờ qua các cuộc điều tra, tình trạng bỏ sót chẩn đoán THA đă và đang xảy ra [3]. Cùng với sự gia tăng các yếu tố nguy cơ thì tỷ lệ người mắc bệnh được phát hiện và quản lý tại cộng đồng còn thấp do ý thức của người dân về bệnh tăng huyết áp và nguồn lực để sàng lọc tăng huyết áp ở cộng đồng vẫn còn hạn chế, điều này gây cản trở cho hoạt động tầm soát tăng huyết áp ở cộng đồng.

\section{KẾT LUÂ̂N}

Tỷ lệ tiền tăng huyết áp ở đối tượng nghiên cứu là $19 \%$ và tỷ lệ tăng huyết áp ở đối tượng nghiên cứu là $21 \%$.

\section{TÀI LIỆ THAM KHẢO}

1. Bô Y Y tế (2019), Báo cáo tổng kết công tác $y$ tế nẳm 2019 và nhiệm vụ, giải pháp chủ yếu năm 2020, Hà Nôi.

2. Bộ Y tế (2015), Điều tra quốc gia yễu tố nguy cơ bềnh không lây nhiễm Việt Nam, Hà Nội.

3. Bồ Y tế (2015), Kế hoạch phòng, chống bệnh không lây nhiễm 2015-2020 tại quyết định 346 Bộ $Y$ tế ngày 30/1/2015

4. Bô̂ Y tê (2006), Về phòng chống một số bệnh không lây nhiếm, Nhà xuất bản $Y$ học, Hà Nội, tr. 9. 39.68. 76. 95

5. Nguyễn Lân Việt (2007), Áp dung một số giải pháp can thiệp thích hợp để phòng chữa bệnh tăng huyết áp ở cộng đồng, Đê tài cấp Bộ, chủ biên, Đại học Y Hà Nội, Hà Nội.

6. Murielle Bochud, 2 Jean-Marc Theler, "19992009 Trends in Prevalence, Unawareness, Treatment and Control of Hypertension in Geneva,Switzerland", http://journals.plos.org/ plosone/article?id $=10.1371 /$

journal.pone.0039877.

7. Fotoula Babatsikou and Assimina Zavitsanou (2010), "Epidemiology of hypertension in the elderly", Health Science Juornal, 4(1), pp. 24-30.

8. Rodríguez-Ramírez Mariana, Luis E SimentalMendía, Manuel González-Ortiz, et al. (2015), "Prevalence of prehypertension in Mexico and its association with hypomagnesemia", American journal of hypertension. 28(8), pp. 1024-1030.

9. World Health Organization (2012), Good health adds life to years: Global brief for World Health Day 2012, WHO Document Product ion Services.

\title{
ĐÁNH GIÁ KẾT QUẢ CộNG HƯởNG TỪ VÀ GIẢI PHẪU BÊ̂NH VỀ DIỆN CẮT CHU VI TRỀN BỆNH NHÂN UNG THƯ TRỰC TRÀNG
}

\author{
Phạm Vũ Minh Hoàng1, Nguyễn Đình Thạch ${ }^{2}$, Nguyễn Duy Khương ${ }^{3}$, \\ Trần Đình Tân ${ }^{1}$, Phan Hữu Huỳnh ${ }^{1}$, Phạm Văn Bình ${ }^{1}$
}

\section{TÓM TẮT}

Mục tiêu: Xác định giá trị của cộng hưởng từ trong đánh giá xâm lấn diện cắt chu vì đối chiếu với kết quả giải phẫu bệnh \& Nhận xét mối liên quan của

\footnotetext{
${ }^{1}$ Bênh viện $K$

${ }^{2}$ Tt Giải phẫu bênh-Sinh học phân tư', Bệnh viện K

${ }^{3}$ Trung tâm Chẩn đoán hình ảnh, Bệnh viện $K$

Chịu trách nhiệm chính: Phạm Vũ Minh Hoàng

Email: pvmh.hmu.nch@gmail.com

Ngày nhận bài: 11.5.2021

Ngày phản biên khoa hoc: 28.6.2021

Ngày duyệt bài: 9.7.2021
}

một số yếu tố với tình trạng diện cắt chu vi. Phương pháp: Mô tả cắt ngang tiến cứu. Kết quả: Độ nhay. độ đặc hiệu, độ chính xác: cộng hưởng từ trong đánh giá xâm lẩn diển cắt chu vi đối chiếu với kết quả giải phẫu bênh lần lướt là: 33,3\% (95\% CI: 4,3 - 77,7\%); 93,7\% (95\% CI: 84,5 - 98,2\%) và 88,4\% (95\% CI: 78,4 - 94,9\%). Ghi nhận các yếu tố: vị trí khối u $(p<0,05)$; xâm lấn thành ruột $(T)$ trên cộng hưởng từ $(p<0,001)$ và đường kính khối u $(p<0,001)$; di căn hạch $(N)(p<0,01)$; xâm lấn quanh thần kinh $(p<0,05)$ ở giải phâuu bệnh có mối liên quan với tình trạng diện cắt chu vi (sự khác biệt có ý nghĩa thống kê). Kết luân: Đố đặc hiệu và độ chính xác của cộng hưởng từ trong đánh giá xâm lấn diện cắt chu vi khá cao; tuy 
nhiên độ nhạy còn thấp. Các yếu tố nguy cơ liên quan với tình trang diên cắt chu vi là: vị trí, đường kính khối u; độ xâm lấn thành ruột $(\mathrm{T})$, mức di căn hạch $(\mathrm{N})$ và tính chất xâm lấn quanh thân kinh.

Từ khoá: Diện cắt chu vi (CRM), cân mạc treo trực tràng (MRF).

\section{SUMMARY \\ EVALUATION OF RESULTS MAGNETIC \\ RESONANCE AND PATHOLOGY ABOUT CIRCUMFERENTIAL RESECTION MARGIN IN RECTAL CANCER PATIENTS}

Objective: Determine the value of magnetic resonance in the invasive assessment of the circumferential resection margin compared with the pathological results and comment on the relationship of some factors with circumferential resection margin status. Methods: Prospective cross - sectional description. Results: The sensitivity, specificity and accuracy of magnetic resonance in the invasive assessment of the circumferential resection margin compared with the pathological results were: $33,3 \%$ (95\% CI: 4,3 - 77,7\%); 93,7\% (95\% CI: 84,5 $98,2 \%)$ và $88,4 \%(95 \% \mathrm{CI}: 78,4-94,9 \%)$. Recording the factors: tumor location $(p<0,05)$; intestinal wall invasion $(T)$ on magnetic resonance $(p<0,001)$ and tumor diameter $(p<0,001)$, lymph node metastasis $(N)$ $(p<0,01)$; perineural invasion $(p<0,05)$ at pathology was associated with circumferential resection margin status (the difference was statistically significant). Conclusion: The specificity and accuracy of magnetic resonance in the invasive assessment of the circumferential resection margin were quite high; however the sensitivity was still low. The risk factors associated with circumferential resection margin status were: tumor location, tumor diameter, intestinal wall invasion $(\mathrm{T})$, lymph node metastasis $(\mathrm{N})$ and perineural invasion.

Keywords: Circumferential resection margin (CRM), mesorectal fascia (MRF).

\section{I. ĐĂTT VẤN ĐỀ}

Lịch sử phẫu thuật ung thư trực tràng (UTTT) triệt căn hiện đại ghi dấu bởi cuộc cách mạng trong kỹ thuật cắt toàn bộ mạc treo trực tràng (TME) được khởi xướng bởi Heald \& cộng sự (CS) (1982) và cùng với sự phối hợp điều trị đa mô thức đã đưa đến những kết quả ngoạn muc về mặt ung thư học. Tuy nhiên, tái phát tại chổ vẫn là vấn đề khiến Nhà ngoại khoa ung thư luôn trăn trở, đặc biệt liên quan tới tình trạng các diện cắt. Trải dọc chiều dài thế kỷ nghiên cứu về UTTT, giới hạn diện cắt dưới thường xuyên được nhắc đến ở các báo cáo, trong khi diện cắt chu vi vòng quanh u chỉ thực sự được chú ý sau mô tả đầu tiên của Quirke \& cs (1986). Diện cắt chu vi (DCCV) được xác định là bề mặt không có phúc mạc cửa mẫu bệnh phẩm trực tràng sau khi mổ xẻ phẫu tích giải phóng di động đoạn trực tràng dưới nếp gấp phúc mạc. Đánh giá tình trạng
DCCV là phép đo khoảng cách ngắn nhất $(\mathrm{mm})$ từ mép ngoài cùng của tổ chức mô chứa tế bào ung thư đến bờ phẫu thuật theo chu vi (nơi được đánh dấu mực) dưới kính hiển vi. Kết luận giải phẫu bệnh (GPB) xâm lấn $\mathrm{DCCV}$ nếu kết quả phép đo $\leq 1 \mathrm{~mm}$, khi đó CRM (+); ngược lại với kết quả $>1 \mathrm{~mm}$, tức là CRM (-). Tình trạng DCCV là một trong những yếu tố tiên lượng độc lập \& quan trọng liên quan tới nguy cơ tái phát tại chỗ, di căn xa cũng như sự sống còn. [1], [3], [4], [5], [6], [7], [8]

Chụp cộng hưởng từ $(\mathrm{CHT})$ vùng chậu là phương pháp tiêu chuẩn để tiên đoán tình trạng DCCV trước mổ và có giá trị tốt nhất trong đánh giá khả năng xâm lấn cân mạc treo trực tràng (MRF). MRF được xác định là cấu trúc viền mảnh với cường độ tín hiệu thấp ở hình ảnh $\mathrm{T} 2 \mathrm{~W}$ trên mặt phẳng cắt ngang (axial). MRF là mặt phẳng phẫu tích trong kỹ thuật TME, như vậy MRF xem như đại diện hay sẽ trở thành DCCV nếu phẫu thuật viên đạt được mức độ TME trọn vẹn lý tưởng. Theo Hiệp hội Chẩn đoán hình ảnh tiêu hoá \& Ổ bụng châu Âu (ESGAR - 2016), nếu khoảng cách ngắn nhất từ bờ ngoài cùng của mô u đến MRF đo được: $\leq 1 \mathrm{~mm}$, tức là $\operatorname{MRF}(+)$; ngược lại $>2 \mathrm{~mm}$ thì MRF $(-)$; còn khi $>1 \mathrm{~mm} \&$ $\leq 2 \mathrm{~mm}$, lúc này tình trạng MRF "đe doạ". [2], [3]

Xuất phát từ thực tiễn lâm sàng cùng với nhận ra chủ đề có giá trị ý nghĩa, mà trong khi ở nước ta hiện nay chưa có công trình chuyên sâu về đánh giá tình trạng $D C C V$ qua phân tích trên CHT \& GPB. Vì vậy, chúng tôi tiến hành nghiên cứu này nhằm mục đích:

- Xác định giá trị của cộng hưởng từ trong đánh giá xâm lấn DCCV đôi chiêuu với kết quả giải phẫu bênhh.

- Nhận xét môi liên quan của một số yếu tố với tinh trạng DCCV.

\section{II. ĐỐI TƯỢNG VÀ PHƯƠNG PHÁP NGHIÊN CỨU}

Với các tiêu chuẩn, đã lựa chọn ra 69 bệnh nhân thoả mãn yêu câu được chẩn đoán xác định ung thư biểu mô trực tràng và điều trị phẫu thuật tại khoa Ngoại Bụng I, Bệnh viện K từ tháng 4/2020 - 5/2021. Nghiên cứu mồ tả cắt ngang tiến cứu và dữ liệu được thu thập, xử lý bằng phần mềm SPSS 25.0.

\section{KẾT QUẢ NGHIÊN CỨU}

3.1 Giá trị của cộng hưởng từ trong đánh giá xậm lấn DCCV đối chiếu với kêt quả giải phẫu bệnh

Bảng 3.1 Đánh giá xâm lấn diên cắt chu vi trên cộng hưởng từ và giải phẩu bệnh

Giải phâu bệnh 


\begin{tabular}{|c|c|c|c|c|}
\hline \multirow{3}{*}{$\begin{array}{c}\text { Cộng } \\
\text { hưởng } \\
\text { từ }\end{array}$} & & CRM(+) & CRM(-) & Tống \\
\cline { 2 - 5 } & MRF (+) & 2 & 4 & 6 \\
\cline { 2 - 5 } & MRF (-) & 4 & 59 & 63 \\
\cline { 2 - 5 } & Tống & $\mathbf{6}$ & $\mathbf{6 3}$ & $\mathbf{6 9}$ \\
\hline
\end{tabular}

$\rightarrow$ Độ nhạy, độ đặc hiệu, giá trị dự đoán dương tính (PPV), giá trị dự đoán âm tính (NPV) và độ chính xác lân lượt là: 33,3\% (95\% CI: 4,3 $77,7 \%$ ); 93,7\% (95\% CI: 84,5 - 98,2\%); 33,3\% (95\% CI: $10,3-68,6 \%) ; 93,7 \%$ (95\% CI: 89,3\% - 96,3\%) và $88,4 \%$ (95\% CI: 78,4 - 94,9\%).

\subsection{Mối liên quan của một số yêu tố với} tình trạng DCCV

Bảng 3.2 Môi liên quan giứa các yêu tố trên cộng hưởng tư với tình trạng DCCV

\begin{tabular}{|c|c|c|c|}
\hline $\begin{array}{l}\text { Các yếu tố } \\
\text { trên cộng } \\
\text { hưởng tứ }\end{array}$ & $\begin{array}{c}\text { MRF } \\
(-)\end{array}$ & $\begin{array}{c}\text { MRF } \\
(+)\end{array}$ & $\begin{array}{c}\text { Giá trị } \\
\qquad p\end{array}$ \\
\hline \multicolumn{4}{|c|}{ Giai đoạn (T) } \\
\hline $\mathrm{T} 1,2$ & $7(11,1 \%)$ & $0(0,0 \%)$ & \multirow{4}{*}{$\begin{array}{c}p< \\
0,001\end{array}$} \\
\hline T3ab & $51(81,0 \%)$ & $1(16,7 \%)$ & \\
\hline T3cd & $4(6,3 \%)$ & $3(50,0 \%)$ & \\
\hline T4a & $1(1,6 \%)$ & $2(33,3 \%)$ & \\
\hline \multicolumn{4}{|c|}{ Giai đoạn (N) } \\
\hline NO & $14(22,2 \%)$ & $0(0,0 \%)$ & \multirow{3}{*}{$\begin{array}{c}p= \\
0,068\end{array}$} \\
\hline N1 & $41(65,1 \%)$ & $3(50,0 \%)$ & \\
\hline N2 & $8(12,7 \%)$ & $3(50 \%)$ & \\
\hline \multicolumn{4}{|c|}{ Vị trí u } \\
\hline Thấp & $2(3,2 \%)$ & $0(0,0 \%)$ & \multirow{5}{*}{$\begin{array}{c}p= \\
0,027\end{array}$} \\
\hline $\begin{array}{l}\text { Trung bình - } \\
\text { thấp }\end{array}$ & $23(36,5 \%)$ & $1(16,7 \%)$ & \\
\hline Trung bình & $16(25,4 \%)$ & $0(0,0 \%)$ & \\
\hline $\begin{array}{l}\text { Trung bình - } \\
\text { cao }\end{array}$ & $12(19,0 \%)$ & $5(83,3 \%)$ & \\
\hline Cao & $10(15,9 \%)$ & $0(0,0 \%)$ & \\
\hline
\end{tabular}

Bảng 3.3 Môí liên quan giữa các yêu tố trên giải phẫu bệnh với tình trạng DCCV

\begin{tabular}{|c|c|c|c|}
\hline $\begin{array}{c}\text { Các yếu tố } \\
\text { trện giải } \\
\text { phẫu bệnh }\end{array}$ & $\begin{array}{c}\text { CRM } \\
(-)\end{array}$ & $\begin{array}{c}\text { CRM } \\
(+)\end{array}$ & $\begin{array}{c}\text { Giá trị } \\
\text { p }\end{array}$ \\
\hline \multicolumn{4}{|c|}{ Vị trí u } \\
\hline Mặt trước & $21(33,3 \%)$ & $2(33,3 \%)$ & \multirow{4}{*}{$\begin{array}{c}p=0,93 \\
6\end{array}$} \\
\hline Mặt sau & $21(33,3 \%)$ & $2(33,3 \%)$ & \\
\hline Mặt bên & $8(12,7 \%)$ & $0(0,0 \%)$ & \\
\hline Vòng nhấn & $13(20,6 \%)$ & $2(33,3 \%)$ & \\
\hline \multicolumn{4}{|c|}{ Chất lượng bệnh phấm } \\
\hline Toàn vẹn & $49(77,8 \%)$ & $3(50,0 \%)$ & \multirow{3}{*}{$\begin{array}{c}p=0,26 \\
8\end{array}$} \\
\hline Gân toàn vẹn & $12(19,0 \%)$ & $3(50,0 \%)$ & \\
\hline Không toàn vẹn & $2(3,2 \%)$ & $0(0,0 \%)$ & \\
\hline \multicolumn{4}{|c|}{ Hình dạng u } \\
\hline Sùi & $23(36,5 \%)$ & $3(50,0 \%)$ & \multirow{4}{*}{$\begin{array}{c}p=0,51 \\
7\end{array}$} \\
\hline Loét & $28(44,4 \%)$ & $2(33,3 \%)$ & \\
\hline Sùi loét & $8(12,7 \%)$ & $0(0,0 \%)$ & \\
\hline Thâm nhiêm & $4(6,3 \%)$ & $1(16,7 \%)$ & \\
\hline \multicolumn{4}{|c|}{ Xâm lấn mạch máu } \\
\hline
\end{tabular}

\begin{tabular}{|c|c|c|}
\hline Có & $17(27,0 \%) 2(33,3 \%)$ & $p=0,66$ \\
\hline Không & $46(73,0 \%) \quad 4(66,7 \%)$ & \\
\hline \multicolumn{3}{|c|}{ Xâm lấn mạch bach huyết } \\
\hline Có & $7(11,1 \%) 2(33,3 \%)$ & \multirow[t]{2}{*}{$p=0,17$} \\
\hline Không & $56(88,9 \%) 4(66,7 \%)$ & \\
\hline \multicolumn{3}{|c|}{ Xâm lấn quanh thân kinh } \\
\hline Có & \begin{tabular}{|c|c|}
$6(9,5 \%)$ & $3(50,0 \%)$ \\
\end{tabular} & \multirow{2}{*}{$\begin{array}{c}p=0,0 \\
26\end{array}$} \\
\hline Không & \begin{tabular}{|l|l|}
$57(90,5 \%)$ & $3(50,0 \%)$ \\
\end{tabular} & \\
\hline \multicolumn{3}{|c|}{ Đố mô hoc } \\
\hline Biệt hoá vừa & $59(93,7 \%) 4(66,7 \%)$ & \multirow{2}{*}{$\begin{array}{c}p=0,08 \\
1\end{array}$} \\
\hline Biệt hoá kém & $4(6,3 \%) \quad 2(33,3 \%)$ & \\
\hline \multicolumn{3}{|c|}{ Đường kính u } \\
\hline$<4$ & $57(90,5 \%) \mid 1(16,7 \%)$ & \multirow{2}{*}{$\begin{array}{c}p<0,0 \\
01\end{array}$} \\
\hline$\geq 4$ & \begin{tabular}{l|l}
$6(9,5 \%)$ & $5(83,3 \%)$ \\
\end{tabular} & \\
\hline \multicolumn{3}{|c|}{ Giai đoạn (T) } \\
\hline T1 & $3(4,8 \%) \quad 0(0,0 \%)$ & \multirow{4}{*}{$\begin{array}{c}p=0,07 \\
6\end{array}$} \\
\hline T2 & \begin{tabular}{l|l}
$8(28,6 \%)$ & $0(0,0 \%)$ \\
\end{tabular} & \\
\hline T3 & $38(60,3 \%) \quad 4(66,7 \%)$ & \\
\hline T4a & \begin{tabular}{l|l}
$4(6,3 \%)$ & $2(33,3 \%)$ \\
\end{tabular} & \\
\hline \multicolumn{3}{|c|}{ Giai đoạn (N) } \\
\hline NO & $40(63,5 \%) \quad 0(0,0 \%)$ & \multirow{3}{*}{$\begin{array}{c}p=0,0 \\
01\end{array}$} \\
\hline N1 & $17(27,0 \%) 3(50,0 \%)$ & \\
\hline $\mathrm{N} 2$ & $6(9,5 \%) \quad 3(50,0 \%)$ & \\
\hline
\end{tabular}

\section{BÀN LUÂ̂N}

4.1 Giá trị của công hưởng từ trong đánh giá xâm lấn DCCV đối chiếu với kết quả giải phẫu bệnh. Qua nghiên cứu, chúng tôi nhận thấy $\mathrm{CHT}$ có độ nhạy, độ đặc hiệu và độ chính xác lần lượt là: $33,3 \%(95 \%$ CI: $4,3-$ $77,7 \%) ; 93,7 \%$ (95\% CI: 84,5 - 98,2\%) và $88,4 \%$ (95\% CI: $78,4-94,9 \%)$. Kết quả này cũng tương tự như của nhóm nghiên cứu đa trung tâm ở châu Âu (MERCURY - 2006), với độ nhạy, độ đặc hiệu và độ chính xác tương ứng là: 59\% (95\% CI: $46-72 \%)$; 92\% (95\% CI: $90-$ $95 \%)$ và $88 \%(95 \% \mathrm{CI}: 85-91 \%)$. Các chuyên gia cũng đồng thuận rằng $\mathrm{CHT}$ là phương pháp tốt nhất có giá trị để dự đoán tình trạng DCCV. Với độ đặc hiệu \& độ chính xác cao của thăm dò cận lầm sàng này cho thấy ưu thế của $\mathrm{CHT}$ trong chẩn đoán xâm lấn MRF. Tình trạng MRF giúp phân tầng nhóm đối tượng theo nguy cơ, từ đó quyết định chiến lược điều trị đa mô thức với UTTT. Vì vậy, cần cân nhắc lựa chọn lập kế hoạch hoá xạ trị tân bổ trợ cho những bênh nhẩn có MRF $(+)$ hay MRF "đe doạ". Tuy nhiên, đô̂ nhạy của $\mathrm{CHT}$ trong đánh giá xâm lấn MRF vẩn còn hạn chế. Thật vậy, khả năng phát hiện chính xác các trường hợp MRF (+) phụ thuộc vào thành phần tham gia xâm nhập $M R F$, theo Suárez \& CS (2020), độ nhạy của CHT trong nhận biết xâm lấn DCCV do hach di căn nhỏ hơn so với khối u nguyên phát và đặc biệt kém tin cây. hơn khi thường đánh giá quá mức đối với 
tình huống sau hoá xạ trị. Do đó, điều này nhấn mạnh giới hạn của $\mathrm{CHT}$ trong vấn đề phát hiện vi di căn. [2], [3], [4]

4.2 Mối liên quan của một số yếu tố với tình trạng DCCV. Nhóm nghiên cứu ghi nhận các yếu tố trên $\mathrm{CHT}$ : vị trí khối u, giai đoạn $(\mathrm{T})$ có mối liên quan với sự hiện diện tế bào $u$ ở DCCV với phép kiểm chính xác Fisher, $p=0,027$ \& $p<0,001$. Từ hơn 2 thập kỷ trước, tác giả Brown \& CS (1999) đã khẳng định vai trò của hình ảnh $\mathrm{CHT}$ lát cắt mỏng trên mă̆t phẳng axial để xác định MRF và sự chính xác trong đánh giá giai đoạn $(T)$, đặc biệt là khối u T3. Quan sát từ bảng 3.2, thẩy rằng các trường hợp xâm lấn MRF chủ yếu khi khối u đã vượt qua lớp cơ $>5 \mathrm{~mm}$ (T3cd, T4a) và vị trí u ở khoảng trực tràng trung bình; xét vê mặt giải phẫu càng xuống thấp mạc treo trực tràng càng mỏng, cho nên mức độ xâm lấn thành ruôt và vị trí u trên $\mathrm{CHT}$ ảnh hưởing tới nguy cơ tình trang DCCV không an toàn. Chúng tôi cũng chưa thấy liên quan giữa tình trạng xâm lấn $\mathrm{MRF}$ với giai đoạn $(\mathrm{N})$ trên $\mathrm{CHT}$, mặc dù ngoài tiêu chuẩn cơ bản về kích thước hạch thì các yếu tố khác như hình thái đường viền và đặc tính tín hiệu của hạch cũng được phân tích phối hợp, tuy nhiên hầu hết các chuyên gia cũng đều cho rằng vấn đề chẩn đoán hạch di căn trên $\mathrm{CHT}$ vẫn chưa thực sự đáng tin cậy. [2], [3], [5]

Kết quả từ bảng 3.3, cho thây sự khác biệt giữa các nhóm vị trí u; chất lượng bệnh phẩm; hình dạng u với tình trạng DCCV là không có ý nghĩa thống kê $(p>0,05)$, tuy nhiên Kang \& cs (2017), [5] thấy rằng khối u tại vị trí mặt trước là một yếu tố nguy cơ độc lập duy nhất với sự hiện diện tế bào u ở DCCV khi phân tích đa biến $(p=0,037)$, kết quả này có thể được giải thích bởi thành trước trực tràng được bao bọc bởi lớp mõ mạc treo ít và mỏng hơn. Chúng tôi ghi nhận chất lượng bệnh phẩm đạt mức độ toàn vẹn và hình dạng u loại sùi, loét chiếm tỳ lệ cao nhất; tác giả Oh \& cs (2012) tìm thấy mối liên quan có ý nghĩa thống kê giữa chất lượng mạc treo trực tràng với tình trạng $\operatorname{DCCV}(p=0,002)$. Thật vậy, Nagtegaal \& cs (2002) chỉ ra trong nhóm BN có $\operatorname{DCCV}(+)$, cho thấy kết quả kỹ thuật TME không hoàn chỉnh ở $44 \%$ các trường hợp, ngược lại nếu DCCV (-) kết quả trên chỉ là $11 \%(p<0,001)[5]$, [6]. Ngoài ra, nhóm nghiên cứu cũng tìm thây mối liên quan có ý nghĩa thống kê giữa tình trạng DCCV với các yếu tố: kích thước khối u $(p<0,001)$, giai đoạn hạch và tính chất xâm lấn quanh thần kinh $(p<0,05)$. So sánh với nghiên cứu của tác giả Oh \& CS (2012), ghi nhận tỷ lệ DCCV $(+)$ trong nhóm đường kính khối $u \geq 4 c m$
$(61,2 \%)$ lớn hơn nhóm u < 4cm $(38,8 \%)$. Sự khác biệt này là có ý nghĩa thống kê $(p<0,001)$. Điều này khẳng định kích thước khối u càng lớn thì nguy cơ DCCV $(+)$ càng cao. Sự sống còn của bênh nhân UTTT không bị ảnh hưởng đáng kề bởi hình thức xâm lấn DCCV, tuy nhiên thây rằng, $\operatorname{DCCV}(+)$ do khối u nguyên phát xâm nhập hay xâm lấn mạch bạch huyết thì có tỷ lệ tái phát tại chỗ cao hơn nhóm do hạch di căn. Xâm lấn quanh thần kinh là một quá trình bệnh lý được đặc trưng bởi sự xâm lấn của khối u vào các cấu trúc thần kinh và lan rộng dọc theo vỏ bao thần kinh. Đây là một yếu tố tiên lượng trong UTTT. Rullier \& cs (2013) cũng ghi nhận xâm lấn quanh thần kinh là yếu tố nguy cơ có ảnh hưởng tới DCCV $(p<0,001)[6],[7]$. Mặc dù các yếu tố khác ở mô bệnh học trong nghiên cứu của chúng tôi như: xâm lấn mạch máu, mạch bạch huyết, độ mô học, và mức độ xâm nhập thành ruột đều chưa ghi nhận mối liên quan với tình trạng DCCV (sự khác biệt không có ý nghĩa thống kê, $p>0,05)$; nhưng với các nghiên cứu khác trên thế giới cũng đều thấy báo cáo có mối liên quan giữa các yếu tố nguy cơ trên với tình trạng DCCV: Park \& cs (2014) [8] thấy rằng xâm lấn bạch huyết và giai đoạn $(T)$ có mối liên hê với tình trạng $\operatorname{DCCV}(p<0,05)$; tuy nhiên tác giả chưa thây liên quan khi phân tích với yếu tố xâm lấn mạch máu ở cả 2 nhóm có \& không hoá xạ trị tân bổ trợ $(p>0,05)$. Rullier \& cs (2013) thì ghi nhận xâm lấn mạch máu là yếu tố tiên lượng độc lập với tình trạng DCCV khi phân tích đa biến. Nhóm nghiên cứu của Oh \& cs (2012), tìm thấy mối liên quan của giai đoạn $(T)$ và độ mô học với tình trạng $\operatorname{DCCV}(p<0,05)$, tuy nhiên tác giả chưa ghi nhận xâm lấn mạch máu và xâm lấn bạch huyết là yếu tố liên quan với tình trạng DCCV ( $>>0,05)$ [6], [7]. Trong tương lai, hứa hẹn với cõ mẫu nghiên cứu lớn và protocol đánh giá chi tiết hơn, chúng tôi sẽ hạn chế sai số và từng bước đưa ra kết quả trên quy mô toàn diện.

\section{KẾT LUÂ̂N}

Qua nghiên cứu về DCCV ở 69 trường hợp UTTT được chụp CHT tiểu khung trước mổ và phân tích mẫu bệnh phẩm sau mổ, chúng tôi thấy rằng giá trị của $\mathrm{CHT}$ trong đánh giá xâm lấn DCCV với độ chính xác đạt 88,4\% (95\% CI: 78,4 - 94,9\%). Bước đầu, nhóm tác giả cũng ghi nhận một số yếu tố nguy cơ liên quan với tình trạng DCCV là: vị trí, đường kính khối u; độ xâm lấn thành ruột $(\mathrm{T})$, mức di căn hạch $(\mathrm{N})$ và tính chất xâm lấn quanh thần kinh.

\section{TÀI LIỆU THAM KHẢO}


1. Quirke P., Durdey P., Dixon M.F., et al. (1986). Local recurrence of rectal adenocarcinoma due to inadequate surgical resection. Histopathological study of lateral tumour spread and surgical excision. Lancet Lond Engl, 2(8514), 996-999.

2. Beets-Tan R.G.H., Lambregts D.M.J., Maas M., et al. (2018). Magnetic resonance imaging for clinical management of rectal cancer: Updated recommendations from the 2016 European Society of Gastrointestinal and Abdominal Radiology (ESGAR) consensus meeting. Eur Radiol, 28(4), 1465-1475.

3. MERCURY Study Group (2006). Diagnostic accuracy of preoperative magnetic resonance imaging in predicting curative resection of rectal cancer: prospective observational study. BMJ, 333(7572), 779.

4. Javier Suárez A, Jiménez $\mathbf{G}$, Arias F, Vera $\mathbf{R}$ (2020). What is the Meaning of the Circumferential Resection Margin Involvement by
Lymph Nodes Detected by Magnetic Resonance?. Clin Surg. 5, 2702. .

5. Kang B.M., Park Y.-K., Park S.J., et al. (2018). Does circumferential tumor location affect the circumferential resection margin status in mid and low rectal cancer?. Asian J Surg, 41(3), 257-263.

6. Oh S.J. and Shin J.Y. (2012). Risk factors of circumferential resection margin involvement in the patients with extraperitoneal rectal cancer. J Korean Surg Soc, 82(3), 165-171.

7. Rullier A., Gourgou-Bourgade S., Jarlier M. et al. (2013). Predictive factors of positive circumferential resection margin after radiochemotherapy for rectal cancer: the French randomised trial ACCORD12/0405 PRODIGE 2. Eur J Cancer Oxf Engl 1990, 49(1), 82-89.

8. Park J.S., Huh J.W., Park Y.A., et al. (2014). A circumferential resection margin of $1 \mathrm{~mm}$ is a negative prognostic factor in rectal cancer patients with and without neoadjuvant chemoradiotherapy. Dis Colon Rectum, 57(8), 933-940.

\section{THỰC TRANG BÊNH SÂU RĂNG Ở HỌC SINH HAI TRƯỜNG TIỂU HỌC HUYẾN ĐOAN HÙNG, TİNH PHÚ THỌ}

\section{TÓM TẮT}

Mục tiêu: Mô tả thực trạng bệnh sâu răng ở hoc sinh hai trường tiểu học huyện Đoan Hùng, tỉnh Phú Thọ năm 2021. Đối tượng và phương pháp nghiên cứu: Nghiên cứu mô tả cắt ngang thực hiện trên 300 hoc sinh tiểu hoc ở huyên Đoan Hùng, tỉnh Phú Thọ. Số liệu được thu thập thông qua phỏng vân học sinh, khám răng, miệng học sinh. Kết quả nghiên cứu: Tỷ lệ sâu răng chung là 96,7\%, trong đó sâu răng sữa là $91,0 \%$ và sâu răng vĩnh viễn là $64,0 \%$; sâu mất trám răng sữa là $7,29 \pm 4,47$ với răng sâu trung bình là $35,79 \pm 3,59$, răng mất do sâu là $0,23 \pm 0,74$ và răng sâu được trám là $1,28 \pm 1,72$; sâu mất trám răng vĩnh viễn là $02,49 \pm 2,35$ với răng sâu trung bình là $1,90 \pm 1,81$, răng mất do sâu là $0,003 \pm 0,06$ và răng sâu được trám là $0,58 \pm 0,85$.

Từ khóa: sâu răng, sâu răng sữa, sâu răng vĩnh viễn, học sinh, tiểu học, Phú Thọ

\section{SUMMARY}

THE SITUATION SITUATION OF DENTAL CARIES AMONG PUPILS AT TWO PRIMARY SCHOOLS IN DOAN HUNG DISTRICT, PHU THO PROVINCE IN 2021

Objective: To descriptive situation of dental caries in students at two primary schools in Doan

\footnotetext{
${ }^{1}$ Trung tâm Y tế Huyện Đoan Hùng, Tỉnh Phú Thọ

${ }^{2}$ Trường Đai hoc Y Dược Thái Nguyên

Chịu trách nhiệm chính: Nguyễn Hồng Chuyên

Email: bschuyen81@gmail.com

Ngày nhận bài: 12.5.2021

Ngày phản biên khoa hoc: 28.6.2021

Ngày duyệt bài: 9.7.2021
}

\section{Nguyễn Hồng Chuyên ${ }^{1}$, Lê Thị Thanh Hoa ${ }^{2}$}

Hung district, Phu Tho province in 2021. Methods: The cross-sectional descriptive study was conducted on 300 primary school children in Doan Hung District, Phu Tho Province. Data were collected by interviews with pupils, dental examinations, oral exams. Results: The overall caries prevalence was $96,7 \%$, of which the prevalence of tooth decay was $91,0 \%$ and the prevalence of permanent decay of pupils was $64,0 \%$; mean dmft was $7,29 \pm 4,47$ with decayed (d) component of $35,79 \pm 3,59$, missing (m) component of $0,23 \pm 0,74$, and filled (f) component of $1,28 \pm 1,72$. ; mean DMFT was $02,49 \pm 2,35$ with decayed (D) component of $1,90 \pm 1,81$, missing (M) component of $0.003 \pm 0,06$, and filled (F) component of $0,58 \pm 0,85$.

Keywords: Dental caries, Tooth decay, primary school pupils, Phu Tho

\section{I. ĐĂT VẤN ĐỀ}

Sâu răng là bệnh lý khá phổ biến ở đối tượng học sinh, gây hậu quả ở nhiều mức độ về sức khoẻ răng miệng và sức khoẻ chung, ảnh hưởng đến chất lượng cuộc sống, nếu không điều trị sẽ tiến triển dẫn đến nhiễm trùng, mất răng...

Các nghiên cứu dịch tễ học gần đây đều ghi nhận thực trạng báo động của sức khoẻ răng miệng toàn câu, ảnh hưởng đến trẻ em cũng như người lớn, răng sữa cũng như răng vĩnh viễn. Điều này đòi hỏi cung cấp thêm các bằng chứng về sự thay đổi của bệnh sâu răng tại thời điểm hiện tại cũng như sự cấp bách của chiến lược y tế công cộng... Trong nghiên cứu của tác giá Yoshiaki Nomura, Ryoko Otsuka, Wit Yee 